\title{
A biochemical evaluation of the erythrocyte glutathione reductase $(E C$ 1 6.4.2) test for riboflavin status
}

\author{
1. Rate and specificity of response in acute deficiency
}

\author{
BY A. M. PRENTICE* AND C. J. BATES $\dagger$ \\ Dunn Nutrition Unit, University of Cambridge and Medical Research Council, Cambridge
}

(Received 31 October 1979 - Accepted 14 July 1980)

1. Acute riboflavin deficiency was produced in weanling rats by feeding a deficient diet and using tail-cups to prevent refection. Animals were killed at weekly interval for 7 weeks, by the end of which they had become severely deficient, and mortality was high.

2. Growth of the deficient animals virtually ceased in the early stages of deficiency; food intake was severely and progressively depressed. Liver: body-weight increased markedly; packed cell volume fell at a late stage only. Pathological signs accumulated throughout the deficiency but were not closely related to the biochemical changes within the deficient group.

3. The activation coefficient (stimulated:basal activity; $A C$ ) of glutathione oxidoreductase (EC 1.6.4.2; glutathione reductase; GR) in erythrocytes rose to a mean value of 3.8 after 3 weeks, and subsequently remained almost constant: this change was not seen in pair-fed or ad lib.-fed controls. Both deficient and pair-fed animals exhibited a twofold reduction in FAD-stimulated erythrocyte GR activity at an early stage. In liver, both deficient and pair-fed groups showed a major progressive fall in FAD-stimulated GR activity, but only the deficient group showed an increase in AC, which occurred towards the later stages of the experiment. In skin, too, the deficient group showed an increase in $\mathrm{AC}$ during the terminal stages.

4. Hepatic, intestinal and brain succinate: (acceptor) oxidoreductase ( $E C$ 1.3.99.1; succinate dehydrogenase) activity fell relatively early during deficiency; in liver and intestine this was at least partly shared by the pair-fed group, and therefore attributable to inanition. Changes in hepatic NADH:(acceptor) oxidoreductase (EC 1.6.99.3; NADH dehydrogenase) activity appeared to be entirely attributable to inanition.

5. An early reduction was observed in hepatic ATP:riboflavin 5-phosphotransferase (EC 2.7.1.26; flavokinase) activity in the deficient group, values falling by nearly half within 1 week, and then remaining almost constant. Similar but smaller changes were seen in renal flavokinase activity. Hepatic ATP: FMN adenylyltransferase (EC 2 7. 7.2; FAD pyrophosphorylase) was unchanged until the third week, at which point it rose sharply to a new plateau in the deficient group; in kidney it did not respond. These changes were not observed in pair-fed or ad-lib.-fed controls.

6. Hepatic flavin levels fell dramatically during the first 2 weeks of deficiency, FAD being conserved at the expense of FMN. Smaller changes were observed in kidney.

7. Of the processes which are affected by riboflavin deficiency, AC of erythrocyte GR (EGRAC) responds earlier, more dramatically and more specifically than most others, with the possible exception of hepatic flavin levels and flavokinase. Potentially, it is therefore a good index of over-all body riboflavin status, but in acute deficiency the rate of response of many variables is not related to the final extent of response; consequently the correlation between EGRAC and other riboflavin-sensitive processes is less satisfactory than it would be in an equilibrium situation.

The erythrocyte $\mathrm{NAD}(\mathrm{P}) \mathrm{H}_{2}$ : glutathione oxidoreductase $(E C$ 1 6.4 .2 ; glutathione reductase; GR) test of riboflavin status has several advantages over other indices of riboflavin nutriture and has become widely used in both epidemiological and experimental studies. However the extent to which the activation coefficient (AC; stimulated:basal activity of erythrocyte GR) reflects riboflavin status in tissues other than the erythrocyte and in other riboflavin-dependent enzyme systems in the body has not been investigated in detail. Thus, although epidemiological studies have often revealed individuals or populations with raised

- Present address: MRC Laboratory, Keneba, The Gambia, West Africa.

$\uparrow$ For reprints. 
AC values it has not been justifiable to infer the presence of other biochemical lesions. Furthermore, cross-sectional correlations between the AC of erythrocyte GR (EGRAC) and clinical signs of riboflavin deficiency have generally been poor (Thurnham et al. 1971; Tillotson \& Baker, 1972; Buzina et al. 1973; Bamji et al. 1979).

Two types of investigation were therefore undertaken in weanling rats, to define the relationship between EGRAC and other riboflavin-dependent processes more precisely. In the first, rats were maintained on a diet virtually devoid of riboflavin and refection was rigorously prevented by the use of tail-cups, since preliminary studies (Prentice \& Bates, 1980) had shown that refection can produce a dramatic temporary remission from deficiency, which interferes with the steady progression to a severely deficient state. In the second type, described in the accompanying paper (Prentice \& Bates, 1981), a chronic marginal deficiency was produced in the absence of tail-cups.

The acute deficiency model illustrated many of the relationships between EGRAC and other riboflavin-sensitive processes, and indicated which are primary effects of riboflavin deficiency and which are probably secondary to inanition and reduced growth rate. The chronic deficiency model, however, proved more satisfactory in comparing processes whose rates of onset were very different.

\section{MATERIALS AND METHODS}

\section{Animals and diets}

Male, weanling Norwegian hooded rats were housed individually in suspended wire cages. Tail-cups were fitted to the deficient and pair-fed control groups to eliminate coprophagy and thus refection (Prentice \& Bates, 1980). The riboflavin-deficient diet contained $(\mathrm{g} / \mathrm{kg}$ ): sucrose 811, acid-washed casein (Glaxo Ltd) 105, salt mixture (Greenfield et al. 1969) 50, cotton-seed oil 30 , choline chloride 2 , cystine 1.5 . The following vitamins were added $(\mathrm{mg} / \mathrm{kg}$ diet): calcium pantothenate 20 , thiamine hydrochloride 3 , pyridoxine hydrochloride 6 , nicotinamide 25 , biotin $1 \cdot 0$, pteroylglutamic acid 1 , cyanocobalamin 0.05 . Each rat received a weekly dose of $300 \mu \mathrm{g}$ retinol, $5 \mu \mathrm{g}$ ergocalciferol, $10 \mathrm{mg} \alpha$-tocopherol and $0.3 \mathrm{mg}$ menadione. The ad lib.-fed controls, which did not have tail-cups, received the same diet except that the content of the following vitamins were $(\mathrm{mg} / \mathrm{kg})$ : pyridoxine hydrochloride 3 , biotin $0 \cdot 1, \alpha$-tocopherol 2, menadione 0.05 , pteroylglutamic acid was omitted entirely (Prentice \& Bates, 1980). The riboflavin-deficient diet contained less than $0.3 \mu \mathrm{g}$ riboflavin $/ \mathrm{g}$, derived from the casein component. To this was added $3 \mathrm{mg}$ riboflavin $/ \mathrm{kg}$ diet for the ad lib.-fed controls, which was considered adequate for optimal growth (Bro-Rasmussen, 1958) and $15 \mathrm{mg}$ riboflavin $/ \mathrm{kg}$ for the pair-fed controls, to compensate for the reduced total food intake in this group.

Pair-fed animals were individually paired with deficient animals, and received the amount of food eaten by the deficient animals on the previous day. Three rats were killed at zero time and a further ninety-nine were divided randomly into three equal groups as indicated previously. At weekly intervals three rats from each group, preselected at the beginning of the experiment, were killed following collection of blood from the tail vein, and samples of liver $(\mathrm{lg})$, both kidneys, the entire brain, skin $(3 \mathrm{~g})$ and ileum $(1 \mathrm{~g})$ were removed for analysis. Each tissue was homogenized in $20 \mathrm{ml}$ buffer, $\mathrm{pH} 7 \cdot 8$, containing (mol/l) sucrose 0.25 , Tris-chloride 0.01 . Owing to high mortality in the deficient group, the experiment was terminated after 7 weeks.

\section{Analytical methods}

Erythrocyte GR. The concentration of oxidized glutathione, $0.9 \times 10^{-3} \mathrm{~mol} / 1$ used was approximately $50 \%$ above the minimum found to ensure saturation of the enzyme from all tissues studied. (A wide range of oxidized glutathione concentrations have been used 
in other published studies: summarized by Prentice, 1977, and it is possible that some of the variation in 'normal' ranges for EGRAC quoted in different studies may be attributable to this).

The concentration of NADPH, $0.075 \times 10^{-3} \mathrm{~mol} / \mathrm{l}$, was close to the saturating concentration. NADPH was added after the oxidized glutathione, to minimize the risk of inactivation by disulphide reduction (Worthington \& Rosemeyer, 1976). In the presence of potassium phosphate buffer (pH 7.4), $0.1 \mathrm{~mol} / \mathrm{l}$, EDTA at $3.3 \mathrm{mmol} / \mathrm{l}$ was found to result in approximately $10 \%$ activation of the erythrocyte enzyme with no change in stimulation by FAD. Addition of potassium chloride, in an attempt to reproduce the chloride-stimulated activation first described by Scott et al. 1963, however was counterproductive, since it caused a reduction in the stimulation by FAD, and no significant increase in the FAD-stimulated activity.

The optimum concentration of FAD for full activation of the enzyme in erythrocyte haemolysates from deficient animals was found to be $8 \mu \mathrm{mol} / 1$, but for the other tissues, $4 \mu \mathrm{mol} / \mathrm{l}$ was chosen as the best compromise between maximal activation of extracts from deficient animals and a small (2-4\%) inhibition of the enzyme in extracts from control animals, which increased as the FAD concentration was further increased. Although it was possible to avoid this inhibition by adding the FAD at an initially high concentration ( $40 \mu \mathrm{mol} / \mathrm{l})$ and then diluting both enzyme and FAD to $1 \mu \mathrm{mol} / 1$ before adding the other reagents (cf. Garry \& Owen, 1976), and for deficient red cell haemolysates this resulted in an approximately $20 \%$ increase in AC above the values obtained with $8 \mu \mathrm{mol} F A D / 1$ added without subsequent dilution, this modification was not used in the main study.

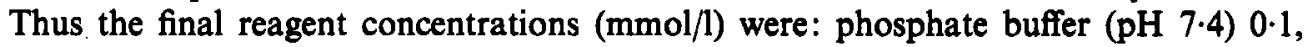
EDTA 3.3, FAD 0.004 or 0.008 , oxidized glutathione 0.9 , NADPH (added last) 0.075 . The change in extinction at $340 \mathrm{~nm}$ was followed for $2-4 \mathrm{~min}$ at $37^{\circ}$ in an automated system based on a Unicam AC60 chemical processing unit.

For the erythrocyte enzyme, sample preparation was based on the ultramicro assay of Thurnham et al. (1970). Blood from the tail vein $(80 \mu \mathrm{l})$ was drawn into a heparinized capillary tube, which was then sealed, centrifuged, and cut to remove the plasma and buffy coat layers. The packed red cells were liberated and haemolysed in $1.0 \mathrm{ml}$ distilled water by crushing the capillary tube, and this preparation was stored at $-20^{\circ}$ for up to 7 weeks without loss of activity, before assay. The activity (/g haemoglobin) was slightly higher, in these samples, than in samples prepared in parallel by the method of Glatzle et al. (1970) using blood obtained by cardiac puncture; however, the AC values were identical.

For other tissues, the soluble fraction of homogenates used for the preparation of submitochondrial particles (see p. 40) was used; the presence of sucrose in the initial buffer had no detectable effect on activities or AC values. Dilutions of the supernatant fractions before assay in phosphate buffer were as follows: liver and kidney $1: 60$, intestine $1: 15$, brain $1: 6$, skin $1: 3$, heart $1: 1 \cdot 5$. The reaction was linearly related to protein concentration at these dilutions. Protein was measured by the method of Lowry et al. (1951), and haemoglobin as cyanmethaemoglobin in a Coulter Haemoglobinometer.

Succinate:(acceptor) oxidoreductase (EC 1.3.99.1; succinate dehydrogenase; SDH). Phenazine methosulphate was selected as the electron acceptor, since it accepts electrons directly from SDH (Kearney \& Singer, 1956), the transfer of electrons to the dye is not rate-limiting, and it can be used with a wide variety of tissues (Bernath \& Singer, 1962). This is not true for other electron acceptors previously used in the determination of SDH in relation to riboflavin deficiency, such as cytochrome $c$ (Axelrod et al. 1942, Nolte et al. (1972); ferricyanide (Burch et al. 1960) or tetrazolium dye (Zaman \& Verwilghen, 1975).

Because intact mitochondria, particularly those from brain, are partially impermeable to phenazine methosulphate, mitochondrial fragments $\left(E_{1}\right)$ were prepared by the method 
of Kopaczyk (1967) which involved addition of sodium cholate to mitochondrial suspensions at a final concentration of $1.0 \mathrm{mg} / \mathrm{mg}$ protein, followed by centrifugation at $105000 \mathrm{~g}$ for $15 \mathrm{~min}$ to retrieve the particles, which were resuspended in phosphate buffer ( $\mathrm{pH} \mathrm{7.4)}$ $0.1 \mathrm{~mol} / 1$. Present evidence suggests that the turnover number and all known catalytic properties of SDH are unaltered in submitochondrial particulate preparations. Using cytochrome oxidase as a recovery marker (Smith, 1958), it was shown that the yield of SDH was $>90 \%$ of the theoretical for mitochondria from all the tissues studied.

To prevent the accumulation of oxaloacetate, which inhibits SDH, cysteine sulphinate, $9 \times 10^{-3} \mathrm{~mol} / \mathrm{l}$ was included in the reaction mixture to destroy it by transamination and desulphination (Bernath \& Singer, 1962).

Since there is insufficient oxygen present to reoxidize leucophenazine methosulphate in the spectrophotometric assay, it is necessary to include 2,6-dichlorophenol indophenol $\left(6 \times 10^{-5} \mathrm{~mol} / \mathrm{l}\right)$ as the terminal electron acceptor (Arrigoni \& Singer, 1962). The reaction rate is dependent on the concentration of phenazine methosulphate, but independent of the concentration of 2,6-dichlorophenol indophenol.

Since the reaction was not performed under anaerobic conditions, potassium cyanide, $1 \mathrm{mmol} / \mathrm{l}$, was also included, to remove any hydrogen peroxide formed from the reaction of leucophenazine methosulphate with oxygen (Kearney \& Singer, 1956); this also prevents the leakage of electrons along the remainder of the electron transport chain to cytochrome c.

Preincubation with sodium succinate $\left(20 \mathrm{mmol} / 1,20 \mathrm{~min}\right.$ at $\left.30^{\circ}\right)$ was included to achieve maximum activation of SDH, and also to ensure that the enzyme was completely protected from inactivation by cyanide (Giuditta \& Singer, 1959).

Because the Michaelis constant $\left(K_{m}\right)$ of SDH varies between different tissues and different preparations, it was considered essential to measure the activity at more than one concentration of phenazine methosulphate in every preparation (Arrigoni \& Singer, 1962) and to calculate the maximum velocity $V_{\max }$ in each instance. In practice, the automated assay for SDH was sufficiently precise for two concentrations $(0.18$ and $1.09 \mathrm{mmol}$ phenazine methosulphate/l) to be sufficient, the coefficient of variation of twenty determinations being 1.9 .

Since the enzyme was unstable at $30^{\circ}$ in the absence of succinate, it was added to the track of the reaction rate analyzer (Unicam AC60) immediately before the addition of succinate for preactivation. Final reagent concentrations in the cuvette were: phosphate buffer $(\mathrm{pH} \mathrm{7.4)} 50 \mathrm{mmol} / 1$, sodium succinate $20 \mathrm{mmol} / 1$, cysteine sulphinate, $9 \mathrm{mmol} / 1$, potassium cyanide $1 \mathrm{mmol} / \mathrm{l}$, calcium chloride $0.75 \mathrm{mmol} / 1$, 2,6-dichlorophenol indophenol $60 \mu \mathrm{mol} / 1$, phenazine methosulphate 0.18 and $1.09 \mathrm{mmol} / 1$. The change in extinction at $600 \mathrm{~nm}$ was followed for $2 \min \left(\epsilon=19000\right.$ for 2,6-dichlorophenol indophenol). $V_{\max }$ values were calculated from double reciprocal plots. Final dilutions of mitochondrial fragments from intact tissues were: liver $1: 35$, kidney $1: 15$, heart, brain, skin and intestine $1: 5$. The fragments were always analysed after less than $24 \mathrm{~h}$ storage at $-20^{\circ}$, and for each tissue it was demonstrated that the activity of isolated fragments was at least as great as that obtained with intact mitochondria.

NADH:(acceptor) oxidoreductase (EC 1.6.99 .3; NADH dehydrogenase). Like succinate dehydrogenase, this enzyme was measured in the sodium cholate-derived mitochondrial fragments $\left(\mathrm{EP}_{1}\right.$; Kopaczyk, 1967) in order to ensure that it was free of the many other NADH-dehydrogenating enzymes present in intact mitochondria. The activity ratio (whole homogenate:mitochondrial fragments) was found to be in the range 1.2-1.7 in the tissues studied. Ferricyanide was chosen as the artificial electron acceptor (Minikami et al. 1962; Beinert et al. 1963) since it couples directly and efficiently with the enzyme even in particulate preparations. Variation of the ferricyanide concentration showed that inhibition occurred 
above $1 \mathrm{mmol} / 1$, but between 0.3 and $1.0 \mathrm{mmol} / 1$ a linear double-reciprocal plot was obtained for all tissues. For liver, kidney, brain and intestine, however, a biphasic response was seen at the lower ferricyanide concentrations, so that two values of $V_{\max }$ and $K_{m}$ were obtained, and it has been suggested that ferricyanide has two reaction sites, one on NADH dehydrogenase and another at cytochrome $c$ (Minikami et al. 1962). By using ferricyanide concentrations of 0.35 and $0.8 \mathrm{mmol} / 1$, however, it was possible to measure the interaction with NADH dehydrogenase alone, and $V_{\max }$ values were calculated as for SDH. The following dilutions of mitochondrial fragments were employed: liver $1: 35$, kidney $1: 35$, heart, brain and intestine $1: 10$, skin $1: 5$. The optimum concentration of NADH was found to be $0.27 \mathrm{mmol} / \mathrm{l}$ and the buffer used was triethanolamine, $\mathrm{pH} 7.8,0.04 \mathrm{~mol} / \mathrm{l}$. The enzyme was added to the track immediately before addition of reagents, and the change in extinction at $420 \mathrm{~nm}$ was followed for $1 \mathrm{~min}$ at $30^{\circ}$.

ATP : riboflavin 5-phosphotransferase (EC 2.7.1.26; flavokinase). The assay was based on McCormick (1961). Liver and kidney samples were homogenized in 9 vol. potassium phosphate buffer (pH 7.0) $0.05 \mathrm{~mol} / 1$ at $4^{\circ}$ in subdued light, and the homogenates were centrifuged at $18000 \mathrm{~g}$ for $30 \mathrm{~min}$. The reaction mixture contained: riboflavin $0.1 \mathrm{mmol} / 1$, ATP $1 \mathrm{mmol} / 1$, zinc sulphate $0.1 \mathrm{mmol} / 1$, potassium phosphate buffer $(\mathrm{pH} 8.0) 75 \mathrm{mmol} / 1$, supernatant fraction enzyme $0.1 \mathrm{ml}$ in $5.0 \mathrm{ml}$ final volume. The mixture was incubated in the dark at $37^{\circ}$ for $30 \mathrm{~min}$, was stopped with trichloroacetic acid, final concentration $50 \mathrm{~g} / 1$, and formation of FMN was measured spectrophotometrically in the supernatant fraction after centrifugation, as described by Kearney \& Englard (1951). A correction was made for FMN phosphatase activity by running control samples in which riboflavin was replaced by FMN, $0 \cdot 1 \mathrm{mmol} / \mathrm{l}$.

ATP:FMN adenylyltransferase (EC 2.7.7.2; Fad pyrophosphorylase). Portions of the homogenates prepared for the flavokinase assay were centrifuged at $2000 \mathrm{~g}$ for $10 \mathrm{~min}$ and then at $10000 \mathrm{~g}$ for $60 \mathrm{~min}$. The assay was a modification of that of DeLuca \& Kaplan (1958). Appropriate, non-inhibitory concentrations of FMN and ATP were found to be $0.5 \mathrm{mmol} / 1$ and $1 \mathrm{mmol} / 1 \mathrm{respectively} \mathrm{for} \mathrm{liver} \mathrm{extracts} \mathrm{and} 0.2 \mathrm{mmol} / 1$ and $0.6 \mathrm{mmol} / 1$ respectively for kidney extracts. All reaction mixtures contained magnesium chloride $1 \mathrm{mmol} / \mathrm{l}$, phosphate buffer (pH 7.5) $25 \mathrm{mmol} / 1$ and $0.2 \mathrm{ml} \mathrm{enzyme-containing} \mathrm{supernatant}$ fraction in a volume of $3.0 \mathrm{ml}$. After $60 \mathrm{~min}$ incubation at $37^{\circ}$ in the dark, trichloroacetic acid, final concentration $70 \mathrm{~g} / \mathrm{l}$, was added, and the samples were cooled rapidly to $4^{\circ}$. FAD was measured fluorimetrically after adjusting the $\mathrm{pH}$ to 1.0 with sulphuric acid $(2 \mathrm{~mol} / \mathrm{l})$ immediately before reading. FMN was assayed by measuring the fluorescence at $\mathrm{pH} 6.8$, and a small (6\%) correction was applied for interference by FMN in the FAD assay. Recovery of internal FAD standards was $92-96 \%$ of the theoretical, so a correction for hydrolysis of FAD was considered unnecessary. Likewise, no correction for FAD pyrophosphatase activity was found to be necessary in the routine assay. It was found that both flavokinase and FAD pyrophosphorylase were stable for several weeks when the enzyme-containing supernatant fractions were stored at $-20^{\circ}$.

FMN phosphatase activity. The assay was that described by McCormick \& Russell (1962) using FMN $0.1 \mathrm{mmol} / 1$; potassium acetate buffer $(\mathrm{pH} 5.0) 75 \mathrm{mmol} / 1$ and enzyme-containing supernatant fraction (as described previously), $0.05 \mathrm{ml}$, in a final volume of $5.0 \mathrm{ml}$. After $30 \mathrm{~min}$ incubation at $37^{\circ}$ in the dark, trichloroacetic acid, final concentration of $50 \mathrm{~g} / \mathrm{l}$, was added and riboflavin was measured spectrophotometrically according to Kearney \& Englard (1951).

Acid-soluble flavin levels in tissues. The method of Bessey et al. (1949) was employed, in which the fluorescence of riboflavin and FMN are measured at $\mathrm{pH} \mathrm{6.8,} \mathrm{with} \mathrm{a} \mathrm{correction}$ for the small contribution by FAD at this $\mathrm{pH}$; that of FAD is measured after hydrolysis to FMN in trichloroacetic acid $(100 \mathrm{~g} / \mathrm{l})$ for $24 \mathrm{~h}$ at $37^{\circ}$, with a correction for FMN and 

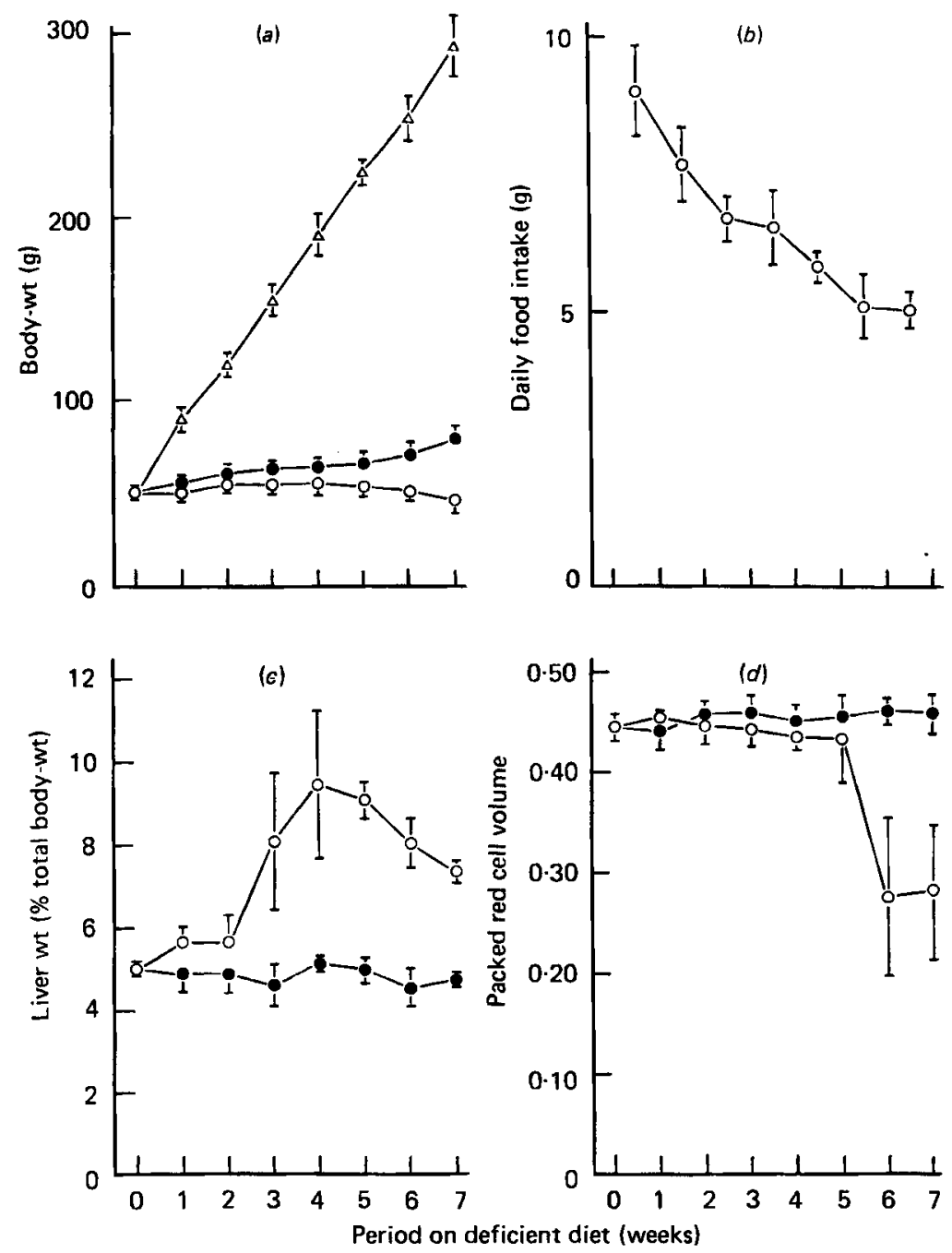

Fig. 1.(a) Growth curves of riboflavin-deficient $(O)$, pair-fed $(O)$ and ad lib.-fed $(\Delta)$ control rats; $(b)$ food intake of deficient $(O)$ animals; $(c)$ relative liver weight of deficient $(O)$ and pair-fed $(O)$ animals; $(d)$ packed red cell volumes of deficient $(O)$ and pair-fed $(O)$ animals. Points are mean values with their standard errors represented by vertical bars $(n 3)$.

Table 1. Appearance of pathological signs and incidence of mortality in the thirty-three riboflavin-deficient animals

\begin{tabular}{lc}
\hline \hline Pathological sign & Day first observed \\
\hline Hair lesions & 7 \\
Foot or tail lesions & 13 \\
Hunched posture & 18 \\
Partial paralysis & 21 \\
Diarrhoea & 25 \\
Deaths & $n$ \\
Days 21-28 & 4 \\
Days 29-35 & 4 \\
Days 36-42 & 4 \\
\hline
\end{tabular}




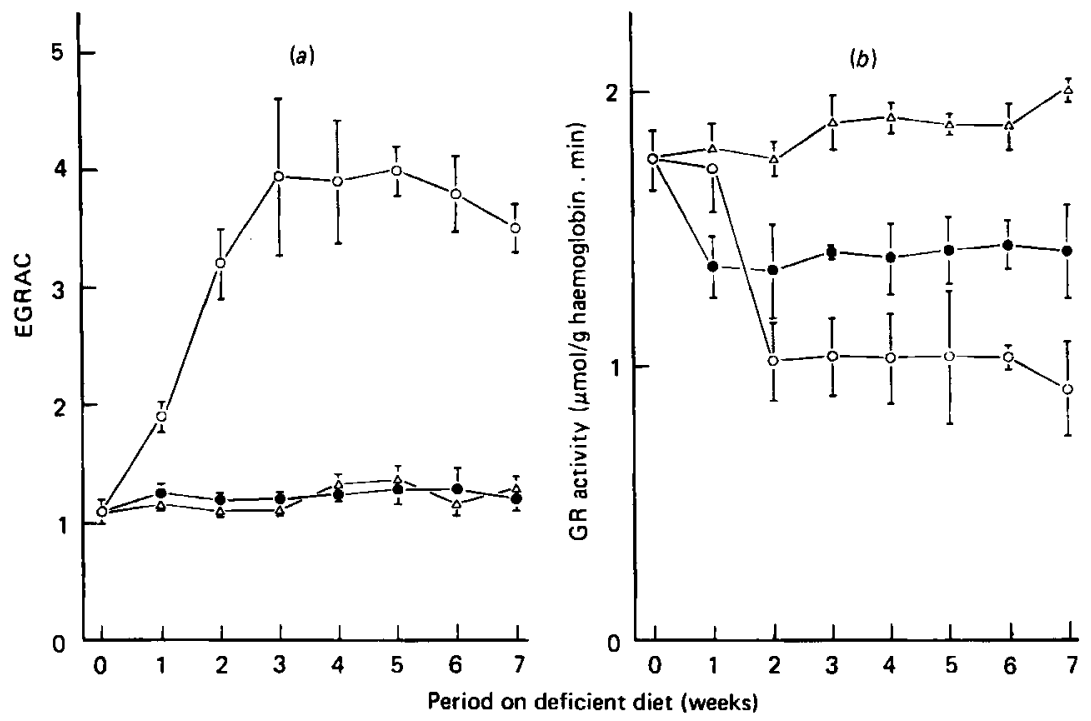

Fig. 2. Activation coefficient (stimulated: basal activity; AC) and FAD-stimulated activity of erythrocyte glutathione reductase $(E C$ 1 $, 6,4.2 ; G R)$ from riboflavin-deficient $(O)$, pair-fed $(O)$ and ad lib.-fed $(\triangle)$ control rats. Points are mean values with their standard errors represented by vertical bars $(n 3)$.

riboflavin; free riboflavin was measured after extraction into benzyl alcohol followed by re-extraction into aqueous buffer in the presence of toluene. The details differed from those of Bessey et al. (1949) in that the final tissue concentration after acid extraction was $10 \mathrm{~g} / \mathrm{l}$, and the volumes were increased threefold in order to use a $3.0 \mathrm{ml}$ (10 mm pathlength) cuvette in a Perkin-Elmer MPF 3 spectrofluorimeter.

$P$ values. Since an approximately Gaussian distribution of values was observed for all the observations which required formal statistical analysis, Students' $t$-test on untransformed values has been used throughout.

\section{RESULTS \\ Growth and pathology}

The earliest demonstrable effect of acute riboflavin deficiency was virtual cessation of growth (Fig. $1(a)$ ). In the pair-fed animals a small increase in body-weight occurred. However, the net increase after 7 weeks was only $31 \mathrm{~g}$, compared with $247 \mathrm{~g}$ in the ad lib.-fed controls. Food intake fell progressively in the deficient group (Fig. 1(b)).

Most of the pathological changes associated with riboflavin deficiency (Goldsmith, 1975) were observed at some stage in the deficient group (Table 1), but not in the control groups. However, within the deficient group, a rank correlation between EGRAC and an estimate of the extent of pathology, obtained by allocating equal weighting to the signs of deficiency listed in Table 1, failed to reveal any significant relationship between the biochemical and the pathological indices.

Liver weight relative to body-weight increased sharply around week 3 (Fig. $1(c)$ ): weeks 0-3 v. weeks $4-7, P<0.001$. Some animals developed obviously fatty livers while others did not; those with fatty livers usually died at an earlier stage of deficiency. During weeks 6-7, a sharp decrease in packed cell volume was observed in the deficient group only (Fig. $1(d)$ ): weeks $0-5$ v. weeks $6+7, P<0.001$. 


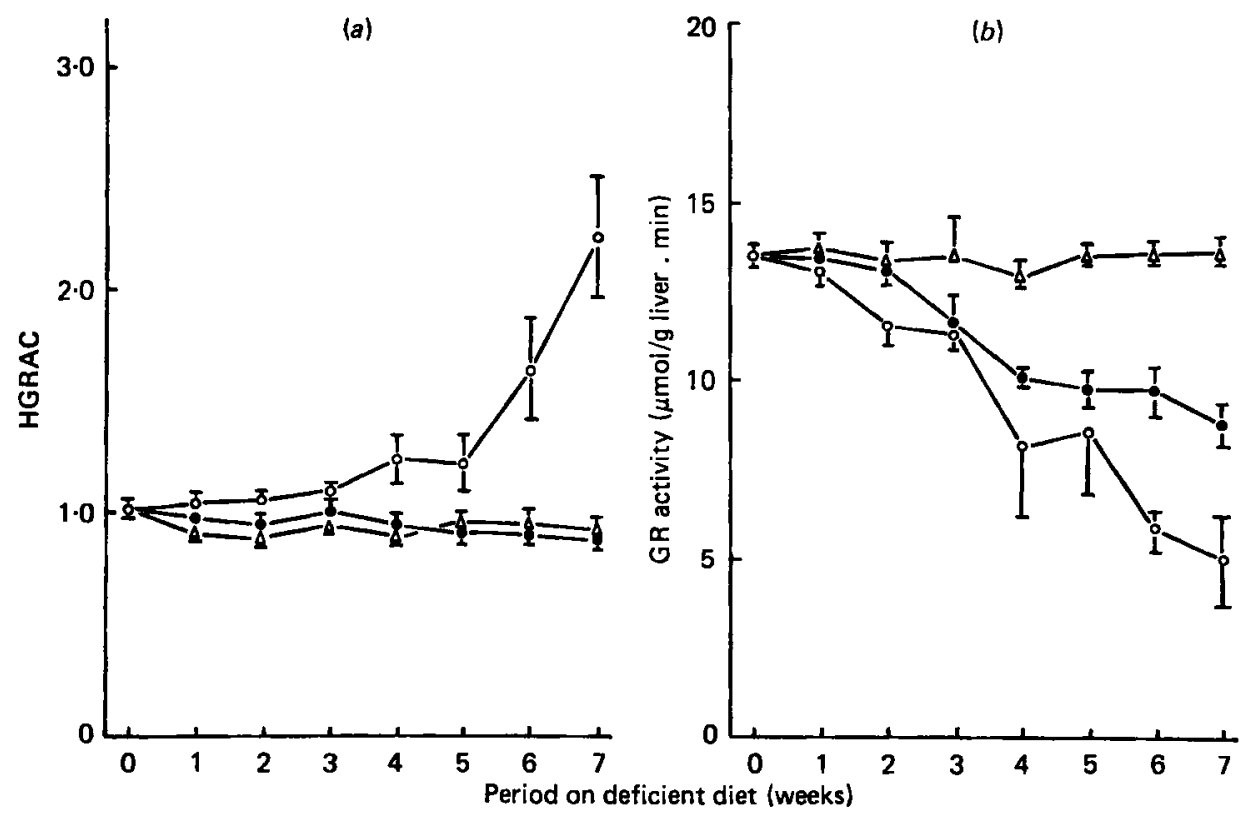

Fig. 3. Activation coefficient (stimulated:basal activity; AC) and FAD-stimulated activity of hepatic glutathione reductase $(E C$ 1 6.4 .2$)$ from deficient $(O)$, pair-fed $(\Theta)$ and ad lib.-fed $(\triangle)$ control rats. Points are mean values with their standard errors represented by vertical bars $(n 3)$.

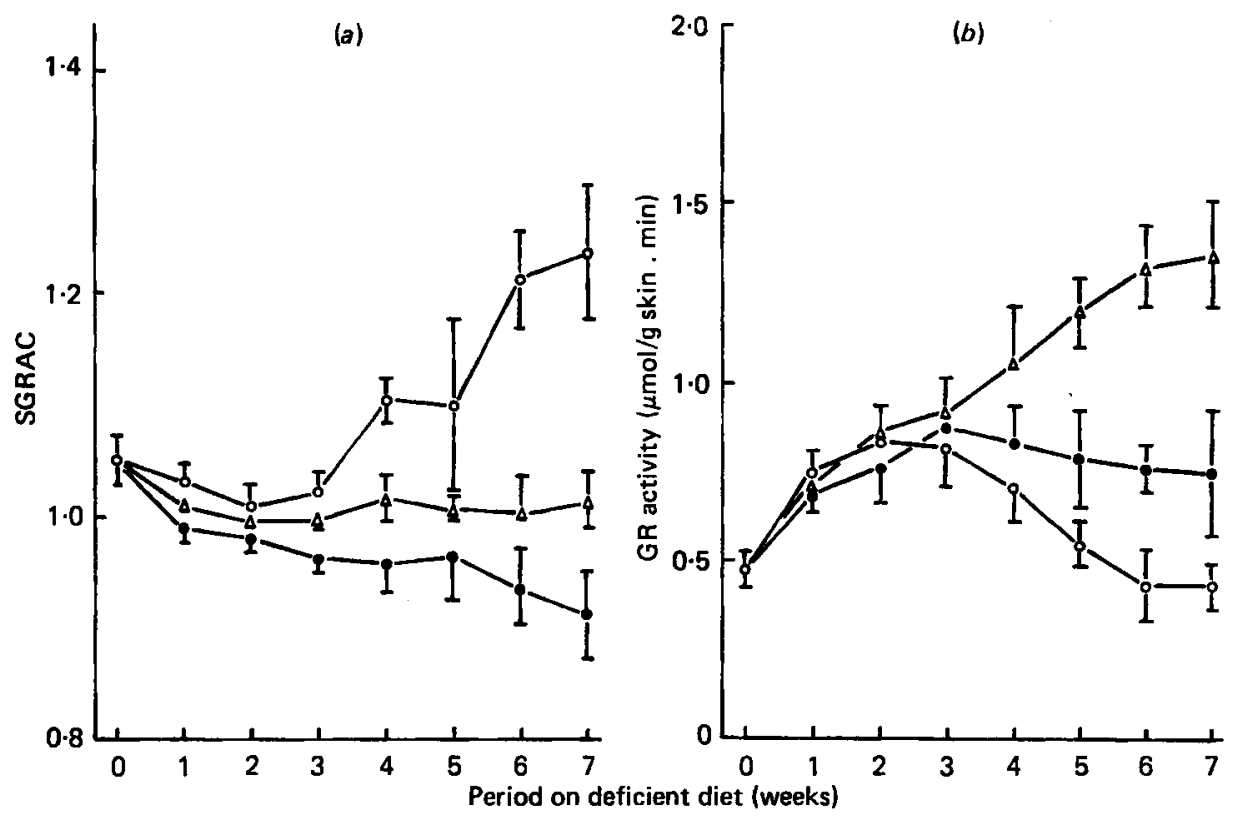

Fig. 4. Activation coefficient (stimulated:basal activity; $A C$ ) and FAD-stimulated activity of skin glutathione reductase $(E C$ 1 .6.4.2) from deficient $(O)$, pair-fed $(O)$ and ad lib.-fed $(\Delta)$ control rats. Points are mean values with their standard errors represented by vertical bars $(n)$ ). 


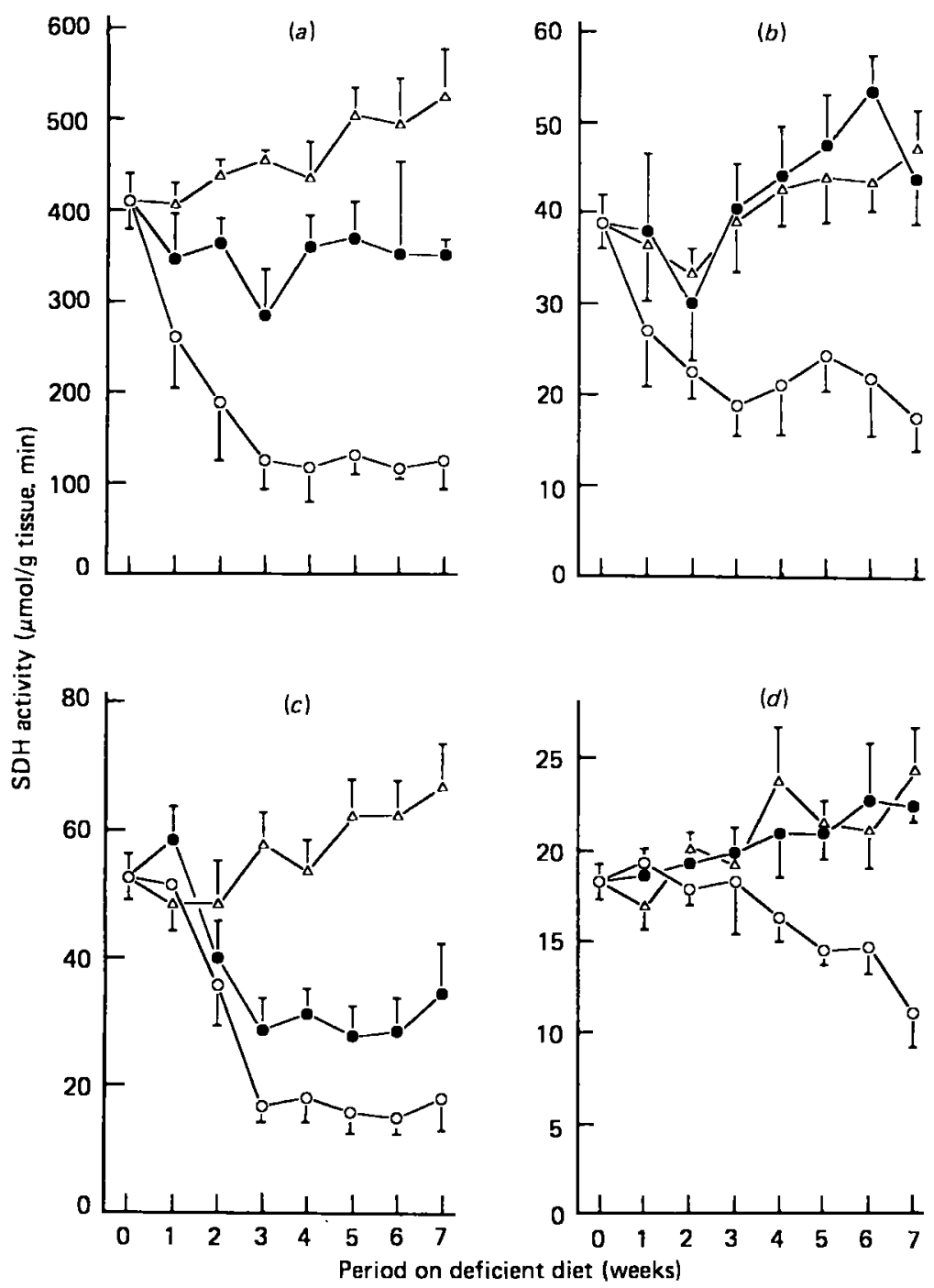

Fig. 5. Succinate dehydrogenase ( $E C$ 1.3.99.1; SDH) activity ( $\mu \mathrm{mol} / \mathrm{g}$ tissue per min) in four tissues: (a) liver, (b) brain, (c) intestine, $(d)$ skin, from riboflavin-deficient (O), pair-fed (O) and ad lib.-fed $(\Delta)$ control rats. Points are mean values with their standard errors represented by vertical bars $(n 3)$.

\section{Glutathione reductase}

EGRAC rose sharply in the deficient group during the first 3 weeks and then remained at a plateau value of 3.8 (Fig. 2(a)). This dramatic increase was not observed in either pair-fed or ad lib.-fed controls. Deficient animals and pair-fed controls both exhibited an early reduction in FAD-stimulated erythrocyte GR activity which was not seen in ad lib.-fed controls (Fig. 2(b)). AC values for hepatic GR (HGRAC) increased at a late stage in the deficient animals but not in the pair-fed or ad lib.-fed controls (Fig. 3(a)); however both deficient and pair-fed groups showed a steady decline in FAD-stimulated hepatic GR activity (Fig. 3(b)). Skin FAD-stimulated GR values rose to a peak at week 2 and then declined by approximately $50 \%$ in the deficient animals (Fig. $4(b)$ ); in the pair-fed group they rose and remained constant, while in the ad lib.-fed group they continued to rise 


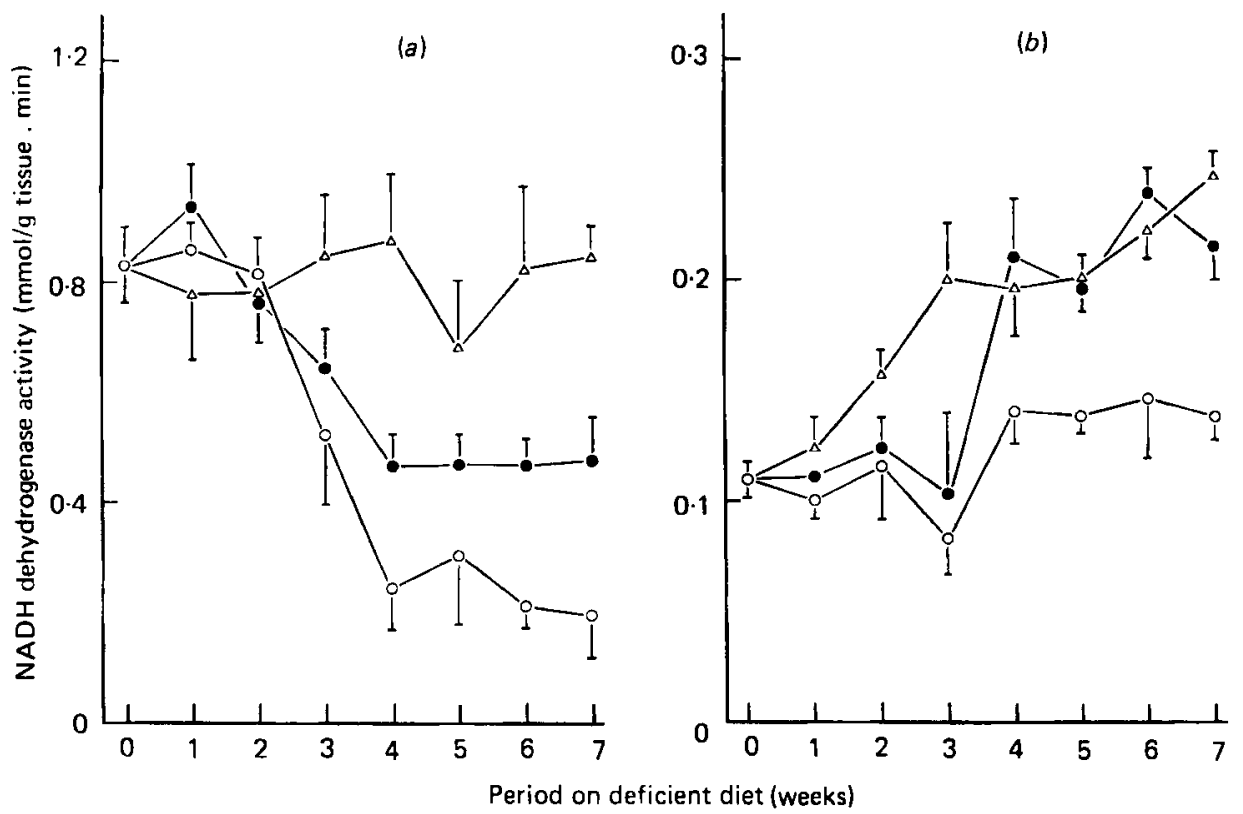

Fig. 6. NADH dehydrogenase (EC 1.6.99.3) activity in (a) liver and (b) intestine from deficient (O), pair-fed $(O)$ and ald lib.-fed $(\triangle)$ control rats. Points are mean values with their standard errors represented by vertical bars $(n)$.

steadily. SGRAC values rose slightly at a late stage in deficient animals (Fig. 4(a)), but remained close to 1.0 in pair-fed and ad lib.-fed controls. AC values for renal and intestinal GR and FAD-stimulated GR were unaffected by deficiency.

\section{Electron transport dehydrogenases}

Hepatic SDH activity declined at an early stage in the deficient animals (Fig. 5(a)), reaching a plateau at approximately week 3 , which is consistent with the pattern of change seen in EGRAC and in hepatic FAD levels (see Figs. 2 and 9). Similar changes were observed in intestinal SDH activity (Fig. 5(c)), and somewhat smaller changes.in brain and skin SDH activity (Figs. $5(b, d)$ ). In brain and skin, these changes in SDH activity appeared to be specific for riboflavin deficiency since the pair-fed control values matched the ad lib.-fed values, but for intestine, and to a lesser extent for liver, the pair-fed control values fell below those of the ad lib.-fed controls.

Hepatic NADH dehydrogenase activity declined sharply between week 2 and week 4 in both deficient and pair-fed animals (Fig. 6(a)). In intestine the age-related increase in activity seen in both $a d$ lib.- and pair-fed controls was not observed in the deficient animals (Fig. 6(b)) although the pattern of activity changes was complex and somewhat irregular. In brain, NADH dehydrogenase activity increased steadily at a similar rate in all three groups of animals, and in skin, no significant changes were observed in any of the three groups.

\section{Flavin metabolizing enzymes and flavin levels}

Flavokinase activity fell sharply during the first two weeks in the livers of the deficient animals, and then remained constant (Fig. 7(a)). No changes were seen in the pair-fed or ad lib.-fed controls. In kidney, the pattern was similar (Fig. 7(b)), but the changes were smaller and more gradual; in skin and brain approximately $40 \%$ reduction in flavokinase was observed in the deficient animals by week 7 .

FAD pyrophosphorylase activity increased markedly at approximately weeks $3-4$ in the 


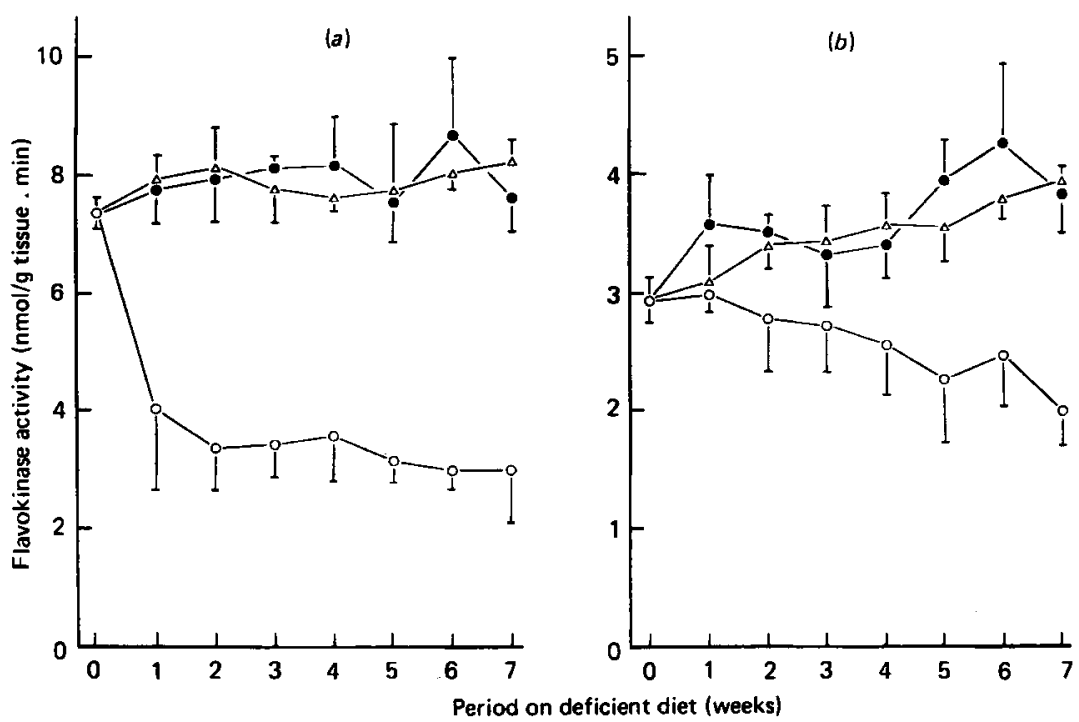

Fig. 7. Flavokinase activity $(E C$ 2.7.1.26) in (a) liver and (b) kidney from deficient (O), pair-fed (O) and $a d$ lib.-fed $(\triangle)$ control rats. Points are mean values with their standard errors represented by vertical bars $(n$ 3).

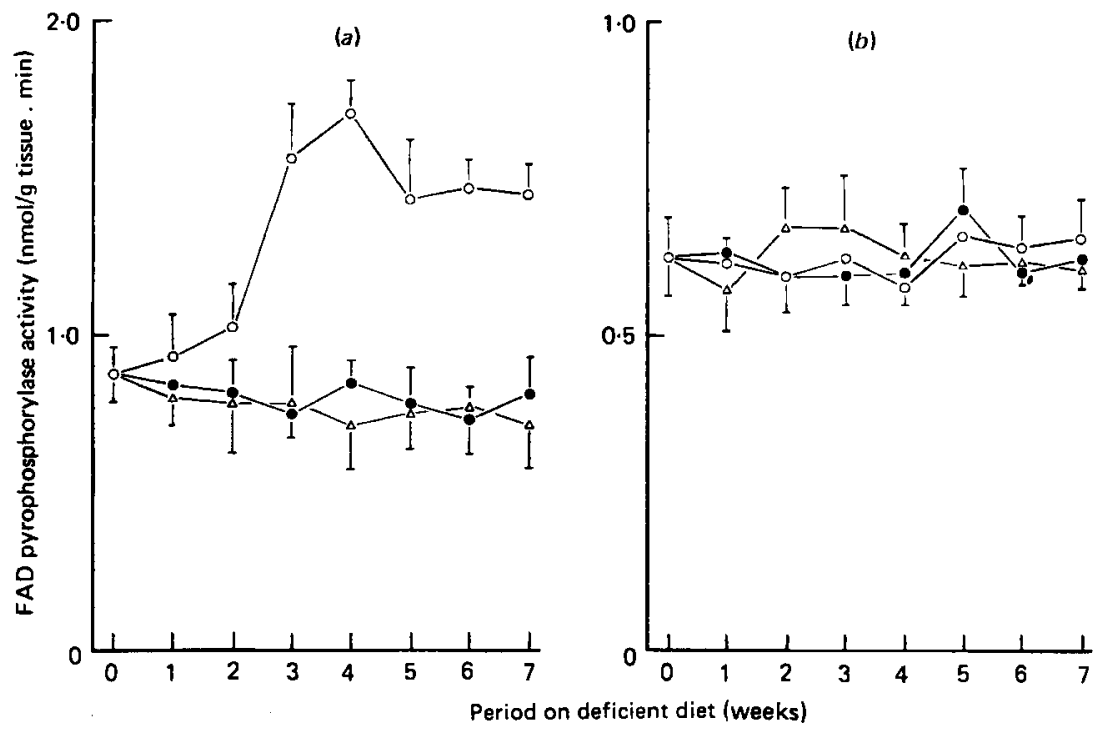

Fig. 8. FAD pyrophosphorylase (EC 2.7.7.2) activity in (a) liver and (b) kidney from deficient $(O)$, pair-fed $(O)$ and ad lib.-fed $(\triangle)$ control rats. Points are mean values with their standard errors represented by vertical bars $(n)$.

livers of deficient animals, but not in the controls (Fig. 8(a)). No corresponding changes were observed in the renal enzyme (Fig. 8(b)). FMN phosphatase activity was unaffected by riboflavin deficiency or inanition in liver and kidney (Prentice, 1977).

Hepatic flavin levels declined sharply in the deficient group during the first 3 weeks, FAD being conserved at the expense of FMN (Fig. 9(a)). These changes were not observed in the control animals. In kidney (Fig. 9(b)), the changes were similar but less marked, and FMN declined relatively less steeply than free riboflavin in this tissue. 


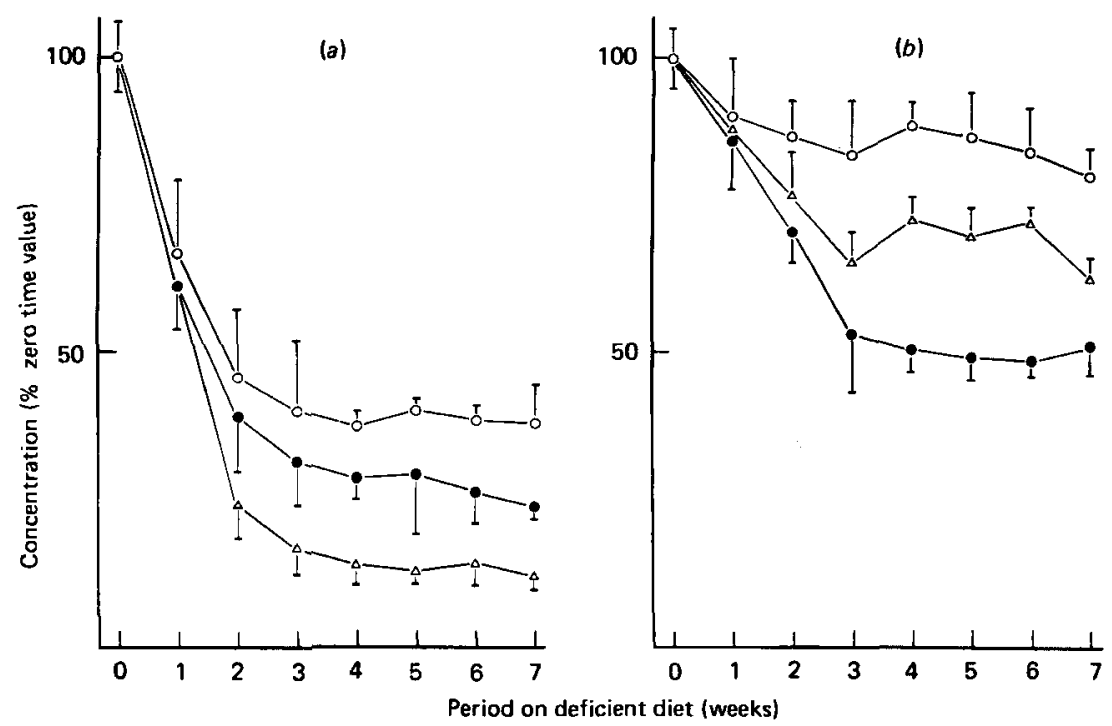

Fig. 9. FAD $(O), F M N(\triangle)$ and free riboflavin (O) concentrations in (a) liver and (b) kidney from riboflavin-deficient rats expressed as a percentage of the zero time values. Pair-fed and ad lib.-fed control values showed no significant deviation from the zero time concentrations which were (mean $\pm \mathrm{sE}: \mu \mathrm{g} / \mathrm{g}$ ): hepatic FAD, $26 \cdot 9 \pm 3 \cdot 7$, hepatic FMN $4 \cdot 2 \pm 0 \cdot 5$, hepatic riboflavin $1 \cdot 40 \pm 0 \cdot 1$, renal FAD $23 \cdot 6 \pm 3 \cdot 0$, renal FMN 13.4 $\pm 2 \cdot 0$, renal riboflavin $1 \cdot 6 \pm 0 \cdot 2$. Points are mean values with their standard errors represented by vertical bars ( $n$ 3).

\section{DISCUSSION}

The failure of the pathological signs to correlate closely with EGRAC or the other biochemical changes observed during deficiency is probably due partly to differences in rate of onset of these changes, and partly to the involvement of secondary stresses such as abrasion and infection, in the aetiology of pathological signs. A closer correlation between clinical signs and biochemical changes was observed in chronic marginal deficiency (Prentice \& Bates, 1981).

The earliest physiological change was the cessation of growth, accompanied by a drastic reduction in food intake (Fig. 1).. Since food utilization efficiency was also somewhat impaired, the pair-fed controls grew somewhat faster than the deficient animals, and this difference probably accounts for the difference between deficient and pair-fed groups in certain inanition-related biochemical changes such as hepatic NADH dehydrogenase activity (Fig. 6).

Increase in liver weight is one of the most consistent physiological changes which are specifically associated with deficiency (cf. Guggenheim \& Daimant, 1959; Burch et al. 1960). Enlarged livers frequently appeared to be fatty in the present study, and were associated with early mortality, which may account for the decline in relative liver weight in the animals which survived until the end of the experiment (Fig. 1(c)).

Anaemia was observed only in the latter stages of deficiency and was very variable (Fig. $1(d)$ ). It has occasionally been reported in previous studies of riboflavin deficiency in rats (Shukers \& Day, 1943; Endicott et al. 1947) and in primates and other species (Foy \& Kondi, 1968; Alfrey \& Lane, 1970), but its occurrence as a primary effect of riboflavin deficiency remains controversial. Although the diets used in the present study contained generous amounts of folic acid, pyridoxine and iron, it is possible that riboflavin deficiency interferes with the metabolism of these haemopoietic nutrients (Miller et al. 1962; Lakshmi \& Bamji, 1974; Sirivech et al. 1977; Zaman \& Verwilghen, 1977) and thus causes a secondary anaemia. 
The mean value for EGRAC in the deficient animals from week 3 onwards (Fig. 2(a)) was as high, or higher, than that reported in previous studies of riboflavin deficiency in rats (Tillotson \& Sauberlich, 1971; Bamji \& Sharada, 1971; Glatzle et al. 1973; Vo-Khactu et al. 1976); the rigorous prevention of reflection probably accounts for this result (Prentice \& Bates, 1980). The fourfold increase in AC, combined with a twofold, inanition-related reduction in FAD-stimulated activity (Fig. 2(b); cf. Bamji \& Sharada, 1972; Vo-Khactu et al. 1976) in the deficient animals should, in theory, result in an eightfold reduction in glutathione-reducing capacity in vivo. Paniker et al. (1970) and Bamji \& Sharada (1971) were unable to demonstrate a decrease in glutathione-reducing capacity in riboflavindeficient rats or human subjects, but recent observations by Hassan \& Thurnham (1977) suggest that glutathione reduction may indeed be impaired, with consequent effects on membrane stability and methaemoglobin reduction. It is also interesting to note that cataract formation may be preceded by a decrease in reduced glutathione levels in the eye (Pirie et al. 1953) which suggests a possible mechanism for cataract formation in riboflavin deficiency.

The mean AC for pair-fed and ad lib.-fed control adult rats was $1 \cdot 28$, which is similar to the mean value of 1.22 obtained in our laboratory for well-nourished human adults, but the specific activity of glutathione reductase/g haemoglobin in rat haemolysates was approximately fivefold lower than in human haemolysates.

For hepatic GR, the increase in AC and decrease in FAD-stimulated activity (Fig. 3) resulted in a fivefold diminution in glutathione-reducing capacity, per unit protein, compared with ad lib.-fed controls. There is disagreement about the response of hepatic GR (cf. Bamji \& Sharada, 1972; Glatzle et al. 1973) which may be related to differences in for example, diets, refection, strain of rat.

For skin GR the increase in AC and decrease in total activity (Fig. 4) produced an approximately fourfold diminution in reducing capacity when compared with ad lib.-fed controls; the results suggest that, once skin GR is depleted of FAD, a large proportion may be irreversibly inactivated.

The insensitivity of renal GR, (confirming the observations of Glatzle et al. 1973) is perhaps surprising in view of the changes in flavin levels (Fig. 7(b)). The failure to detect raised AC values for intestinal GR, despite the severity of the deficiency, is not consistent with the observations of Glatzle et al. (1973), but the reason for this discrepancy is not known.

The magnitude of the decrease in SDH activity observed in several tissues (Fig. 5) underscores the fact that covalent attachment of flavin coenzyme does not, as might be expected, necessarily protect this enzyme against the effects of reduced riboflavin availability. The decrease in hepatic SDH activity (Fig. 5(a)) is partly offset by the increase in liver weight in the deficient animals; the magnitude of the decrease is similar to that observed by Kim $\&$ Lambooy (1969) and as these authors have noted, the rate is consistent with loss of enzyme from pre-existing mitochondria as well as from newly-formed ones. The present results differ from those of Kim \& Lambooy (1969) in that pair-feeding caused a reduction, not an increase, of activity in comparison with ad lib.-fed controls. However, this may perhaps be attributable to differences in the assay techniques used. The change in brain SDH (Fig. $5(b)$ ) was surprising in view of the relative resistance of brain in other respects (Burch et al. 1960) but is consistent with the $40 \%$ reduction in FAD observed by Bessey et al. 1949, and it is of interest that Pinto \& Rivlin (1979) were able to increase covalently bound flavin levels, but not total FAD, in cerebrum by thyroid hormone treatment. For most tissues, SDH activity is thought not to be rate limiting in over-all electron transport (Singer, 1966); it is therefore paradoxical that the reduction in SDH activity appears to result in substantially reduced substrate oxidation (Axelrod et al. 1942; Burch et al. 1960; Zaman \& Verwilghen, 1975). Recently, however, Hoppel et al. (1979) showed that the oxidation of succinate by 
Table 2. Classification of response patterns during acute riboflavin deficiency

\begin{tabular}{|c|c|c|}
\hline Classification & Response & Factors affected \\
\hline 1 & $\begin{array}{l}\text { Rapid early change approaching a } \\
\text { constant plateau; no corresponding } \\
\text { change in pair-fed controls }\end{array}$ & $\begin{array}{l}\text { Increase in EGRAC. } \\
\text { Decrease in brain SDH. } \\
\text { Decrease in hepatic flavokinase }(E C 2.7 .1 .26) \\
\text { Decrease in hepatic and renal flavin concentration }\end{array}$ \\
\hline 2 & $\begin{array}{l}\text { Similar to type } 1 \text {, but complicated by } \\
\text { inanition-related changes seen in pair-fed } \\
\text { controls }\end{array}$ & $\begin{array}{l}\text { Decrease in erythrocyte GR } \\
\text { FAD-stimulated activity. } \\
\text { Decrease in hepatic, and failure to } \\
\text { increase by intestinal, SDH activities. }\end{array}$ \\
\hline 3 & $\begin{array}{l}\text { Progressive change throughout } \\
\text { deficiency; no major inanition effect }\end{array}$ & $\begin{array}{l}\text { Decrease in renal flavokinase. } \\
\text { Increase in SGRAC. }\end{array}$ \\
\hline 4 & $\begin{array}{l}\text { Similar to type } 3 \text {, but complicated by } \\
\text { inanition-related changes seen in pair-fed } \\
\text { animals }\end{array}$ & $\begin{array}{l}\text { Decrease in hepatic } \\
\text { GR and skin GR FAD-stimulated } \\
\text { activities. } \\
\text { Decrease in hepatic NADH } \\
\text { dehydrogenase (EC 1.6.99.3) activity. }\end{array}$ \\
\hline 5 & $\begin{array}{l}\text { Delayed change, reaching a plateau; no } \\
\text { inanition effect }\end{array}$ & $\begin{array}{l}\text { Increase in hepatic } F A D \\
\text { pyrophosphorylase }(E C 2.7 .7 .2) \\
\text { activity. } \\
\text { Increase in liver weight (relative to body-weight). }\end{array}$ \\
\hline 6 & $\begin{array}{l}\text { Changes mainly during the last } 2-3 \\
\text { weeks of deficiency }\end{array}$ & $\begin{array}{l}\text { Increase in HGRAC and decrease in free } \\
\text { apoenzyme levels (difference between } \\
\text { FAD-stimulated and unstimulated } \\
\text { activity). } \\
\text { Decrease in skin SDH activity. } \\
\text { Decrease in packed cell volume. }\end{array}$ \\
\hline 7 & $\begin{array}{l}\text { No detectable change throughout } 7 \\
\text { weeks deficiency }\end{array}$ & $\begin{array}{l}\text { Skin and brain NADH dehydrogenase activity. } \\
\text { Hepatic and renal 'FMN phosphatase' activity. } \\
\text { Renal FAD pyrophosphorylase activity. }\end{array}$ \\
\hline \multicolumn{3}{|c|}{$\begin{array}{c}A C \text {, activation coefficient (stimulated : basal activity); GR, glutathione reductase (EC 1.6.4.2); SDH, succinate } \\
\text { dehydrogenase }(E C \text { 1.3.99.1). }\end{array}$} \\
\hline
\end{tabular}

isolated mitochondria is affected only at a relatively late stage of riboflavin deficiency, other mitochondrial oxidations being much more sensitive.

The decrease in hepatic NADH dehydrogenase (Fig. 6(a)) is probably attributable to inanition, and the magnitude of the change is similar to that observed by Burch $e t$ al. (1960). No reactivation could be achieved in vitro with FMN (1-100 $\mu \mathrm{M})$. It is paradoxical that so little specific reduction in NADH dehydrogenase activity occurs despite the large changes in total hepatic FMN content (Fig. 9(a)), particularly since FMN is not covalently bound to the enzyme (Hatefi et al. 1962). The failure, in the deficient animals, to show the normal age-related increase in intestinal NADH dehydrogenase activity (Fig. $6(b)$ ) appears to have been a specific effect of riboflavin deficiency, unlike the differences observed in the other tissues.

The reduction in hepatic flavokinase (Fig. 7(a)) was similar to that observed by Fass \& Rivlin (1969), but smaller than that reported by Nolte et al. (1972). Clearly it is one of the first enzymes to respond after the onset of deficiency, and Merrill et al. (1978) have shown that it is restored within $6 \mathrm{~h}$ of re-feeding riboflavin. FAD pyrophosphorylase responded 
somewhat later (Fig. 8(a)), and the relative changes in FAD and FMN in liver (Fig. 9(a)) were consistent with the changes in these enzymes. FAD was conserved at the expense of FMN by the increase in FAD pyrophosphorylase in liver, but the latter change was not observed in kidney (Figs. 8(b), $9(b)$ ). The constancy of FAD levels as a proportion of total flavins in all tissues studied except liver suggests that the increase in FAD pyrophosphorylase activity may be confined to liver.

These adaptive changes help to explain the control of 'floor' and 'ceiling' levels of tissue riboflavin levels (Rivlin \& Langdon, 1966), and may also help to explain the different sensitivity to deficiency observed in different tissues (cf. Burch et al. 1960). FMN phosphatase activity on the other hand, was unaffected by riboflavin deficiency in any of the organs studied, and this and other properties suggest that it may not be specific for FMN (Prentice, 1977).

The different types of response observed in those variables which are affected by riboflavin deficiency, are summarized in Table 2. Changes in EGRAC were closely matched by changes in hepatic flavokinase activity, hepatic and renal flavin concentrations and brain SDH activity, but all other factors either changed more slowly, or were complicated by inanition-related effects. Since EGRAC (unlike unstimulated erythrocyte GR activity) was unaffected by inanition, and since it was highly sensitive at the early stages of acute deficiency, it fulfils the basic requirements of a biochemical index of deficiency. On the other hand, the considerable variation in rate of response of different riboflavin-sensitive processes, coupled with the fact that the rate or time of onset is not closely related to the eventual magnitude of the response, makes the acute deficiency model relatively unsatisfactory in assessing EGRAC as an index of riboflavin status. A more satisfactory model would be one in which status equilibrium is reached at a constant riboflavin intake, and this approach is examined in the accompanying paper (Prentice \& Bates, 1981).

\section{REFERENCES}

Alfrey, C. P. \& Lane, M. (1970). Semin. Haemat. 7, 49.

Arrigoni, O. \& Singer, T. P. (1962). Nature, Land. 193, 1256.

Axelrod, A. E., Swingle, K. F. \& Elvehjem, C. A. (1942). J. biol. Chem. 145, 297.

Bamji, M. S., Rameshwar Sarma K. V. \& Radhaiah, G. (1979). Br. J. Nutr. 41, 431.

Bamji, M. S. \& Sharada, D. (1971). Clinica. chim. Acta. 31, 409.

Bamji, M. S. \& Sharada, D. (1972). J. Nutr. 102, 443.

Beinert, H., Palmer, G., Cremona, T. \& Singer, T. P. (1963). Biochem. biophys. Res. Commun. $12,432$.

Bernath, P. \& Singer, T. P. (1962). Meths. Enzym. 5, 597.

Bessey, O. A., Lowry, O. H. \& Love, R. H. (1949). J. biol. Chem. 180, 755.

Bro-Rasmussen, F. (1958). Nutr. Abstr. Rev. 28, 1.

Burch, H. B., Hunter, E. F., Combs, A. M. \& Schutz, B. A. (1960). J. biol. Chem. $235,1540$.

Buzina, R., Brodarec, A., Jušić, M., Milanović, N., Kolombo, V. \& Brubacher, G. (1973). Int. Z. Vitamforsch. 43, 401.

De Luca, C. \& Kaplan, N. O. (1958). Biochim. biophys. Acta 30, 6.

Endicott, K. M., Kornberg, A. \& Ott, M. (1947). Blood 2, 164.

Fass, S. \& Rivlin, R. S. (1969). Am. J. Physiol. 217, 988.

Foy, H. \& Kondi, A. (1968). Am. J. clin. Nutr. 26, 653.

Garry, P. J. \& Owen, G. M. (1976). Am. J. clin. Nutr. 29, 663.

Giuditta, A. \& Singer, T. P. (1959). J. biol. Chem. 234, 666.

Glatzle, D., Körner, W. F., Christeller, S. \& Wiss, O. (1970). Int. Z. Vitamforsch. 40, 166.

Glatzle, D., Weiser, H., Weber, F. \& Wiss, O. (1973). Int. Z. Vitamforsch. 43, 187.

Goldsmith, G. A. (1975). In Ribofiavin, p. 221 [R. S. Rivlin, editor]. New York: Plenum Press.

Greenfield, H., Briggs, G. M., Watson, R. G. J. \& Yudkin, J. (1969). Proc. Nutr. Soc. 28, $43 A$.

Guggenheim, K. \& Daimant, E. J. (1959). Br. J. Nutr. 13, 61.

Hassan, F. M. \& Thurnham, D. I. (1977). Int. Z. Vitamforsch. 47, 349.

Hatef, Y., Haavik, A. G. \& Grifiths, D. E. (1962). J. biol. Chem. 237, 1076.

Hoppel, C., Di Marco, J. P. \& Tandler, B. (1979). J. biol. Chem. 254, 4164.

Horwitt, M. K. (1972). In The Vitamins, vol. 5, p. 73 [W. H. Sebrell and R. S. Harris, editors]. New York: Academic Press. 
Kearney, E. B. \& Englard, S. (1951). J. biol. Chem. 193, 821.

Kearney, E. B. \& Singer, T. P. (1956). J. biol. Chem. $219,963$.

Kim. Y. S. \& Lambooy, J. P. (1969). J. Nutr. 98, 467.

Kopaczyk, K. C. (1967). Meths. Enzym. 10, 253.

Lakshmi, A. V. \& Bamji, M. S. (1974). Br. J. Nutr. 32, 249.

Lowry, O. H., Rosebrough, N. J., Farr, A. L. \& Randall, R. J. (1951). J. biol. Chem. 193, 265.

McCormick D. B. (1961). Proc. Soc. exp. Biol. Med. 107, 784.

McCormick, D. B. \& Russell, M. (1962). Comp. Biochem. Physiol. 5, 113.

Merrill, A. H., Addison, R. \& McCormick, D. B. (1978). Proc. Soc. exp. Biol. Med. 158, 572.

Miller, Z., Poncet, I. \& Takacs, E. (1962). J. biol. Chem. 237, 968.

Minikami, S., Ringler, R. L. \& Singer, T. P. (1962). J. biol. Chem. 237, 569.

Nolte, J., Brdiczka, D. \& Staudte, H. W. (1972). Biochim. biophys. Acta 268, 611.

Paniker, N. V., Srivastava, S. K. \& Beutler, E. (1970). Biochim. biophys. Acta 215, 456.

Pinto, J. \& Rivlin, R. S. (1979). Archs Biochem. Biophys. 194, 313.

Pirie, A., van Heyningen, R. \& Boag, J. W. (1953). Biochem. J. 54, 682.

Prentice, A. M. (1977). The biochemical effects of riboflavin deficiency. PhD Thesis, University of Cambridge.

Prentice, A. M. \& Bates, C. J. (1980). Br. J. Nutr. 43, 171.

Prentice, A. M. \& Bates, C. J. (1981). Br. J. Nutr. 45, 53

Rivlin, R. S. \& Langdon, R. G. (1966). Adv. Enz. Reg. 4, 45.

Scott, E. M., Duncan, I. W. \& Ekstrand, V. (1963). J. biol. Chem. 238, 3928.

Shukers, C. F. \& Day, P. L. (1943). J. Nutr. 25, 511.

Singer, T. P. (1966). In Comprehensive Biochemistry, vol. 14, p. 127. [M. Florkin and E. H. Stotz, editors]. Amsterdam: Elsevier.

Sirivech, S., Driskell, J. \& Frieden, E. (1977). J. Nutr. 107, 739.

Smith, L. (1958). Methods of Biochemical Analysis. 2, 427 [D. Glick, editor]. New York: Interscience Publishers.

Thurnham, D. I., Migasena, P. \& Pavapootanon, N. (1970). Mikrochim. Acta 5, 988.

Thurnham, D. I., Migasena, P., Vudhivai, N. \& Supawan, V. (1971). S.E. Asian J. Trop. Med. Publ. Hlth 2, 552.

Tillotson, J. A. \& Baker, E. M. (1972). Am. J. clin. Nutr. 25, 425.

Tillotson, J. A. \& Sauberlich, H. E. (1971). J. Nutr. 101, 1459.

Vo-Khactu, K. P., Sims, R. L., Clayburgh, R. H. \& Sanstead, H. H. (1976). J. Lab. clin. Med. $87,741$.

Worthington, D. J. \& Rosemeyer, M. A. (1976). Eur. J. Biochem. 67, 231.

Zaman, Z. \& Verwilghen, R. L. (1975). Biochem. biophys. Res. Commun. 67, 1192.

Zaman, Z. \& Verwilghen, R. L. (1977). Biochem. Soc. Trans. 5, 306. 